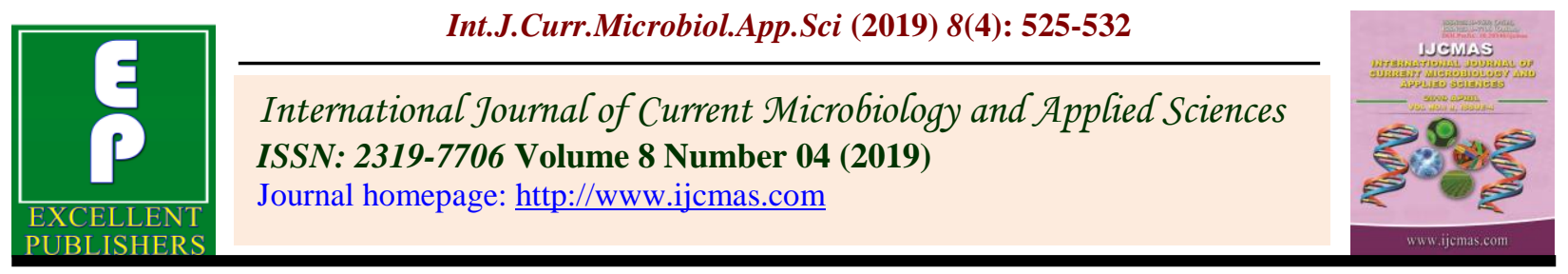

Original Research Article

https://doi.org/10.20546/ijcmas.2019.804.057

\title{
Factors Associated with Embryonic Mortality of Eggs of Vanaraja Breeder Chicken Reared on Deep Litter System
}

\author{
Sujata Dey ${ }^{1}$, Rajarshi Samanta ${ }^{2}$, Subhransu Pan $^{2}$, \\ Bikas Debnath $^{3}$ and Asish Debbarma ${ }^{4}$ \\ ${ }^{1}$ Govt. of Tripura, India \\ ${ }^{2}$ Department of Livestock Production Management, West Bengal University of Animal and \\ Fishery Science, 37, K. B. Sarani, Kolkata-700037, India \\ *Corresponding author
}

\section{A B S T R A C T}

K e y w o r d s
Vanaraja,
Embryonic
mortality, Pre
incubation storage,
Egg shape index,
Shell thickness
Article Info
Accepted:
07 March 2019
Available Online:
10 April 2019

The present study was aimed to explore embryonic mortality pattern of fertile eggs of Vanaraja chicken reared on deep litter system. The study was conducted in the year 2016 at Hatchery Unit of West Bengal University of Animal and Fishery Sciences, Mohanpur campus (Nadia District). Birds were divided in 3 age groups as 27 to 40,41 to 72 and 73 to 92 weeks. Eggs were grouped into three categories; 38 to $41.3,41.6$ to 54.8 and $>55 \mathrm{~g}$. Eggs were stored with the small end pointed downward for 1, 2, 3, 4, 5, 6 days and 86, $144,140,156,155,148$ numbers of eggs, respectively, introduced to the setter. There was no significant effect of flock age, egg weight, pre-incubation storage $(\mathrm{p}<0.05)$ on embryonic mortality but significant difference was seen in embryonic mortality when shape index is $>75 \%$ with both egg shape index range i.e. 64 to 71.96 and 72 to $74.97 \%$, but no significant difference among $64-71.96$ and $72-74.97 \%$. There was significant difference in embryonic mortality when shell thickness was 0.22 to $0.31 \mathrm{~mm}$ with both shell thickness groups i.e. 0.15-0.21 and $>0.32 \mathrm{~mm}$, but no significant differences was found in between $0.15-0.21 \mathrm{~mm}$ and $>0.32 \mathrm{~mm}$ shell thickness groups. Results from this study concluded that embryonic mortality of eggs of vanaraja chicken was influenced by shell thickness and shape index of eggs.

\section{Introduction}

The demand of poultry and its products in India is very high as it has no ethical issues. Introduction of improved breeds, strains, varieties shows an increasing trend in the production. Project Directorate on Poultry (ICAR), Hyderabad has developed a suitable germplasm i.e. Vanaraja for backyard or range farming system. The embryonic mortality of domestic fowl (Gallus gallus domesticus), has progressively increased day by day, previously when flock sizes were small the embryonic mortality rarely exceeded 10\% (Alexis and Romanoff, 1949). Payne (1919) observed embryonic mortality is especially high between third and fifth days of incubation and again on nineteenth day 
approximately. To increase reproductive efficiency, it is necessary to assess the infertility and embryonic mortality that leads to hatching failure. Hatching failure results from two main causes: ova failed to be fertilized or fertilized egg failed to hatch in addition to embryonic mortalities occurred at any stage of development (Birkhead et al., 2008). Approximately $20 \%$ of eggs normally did not hatch; the majority of this expected percentage of embryonic mortality occurred during the first and last weeks of incubation (Lyons, 2003). The most influential egg parameters are: egg weight, shell thickness and egg shape index. The average value of the egg quality traits are required for the embryo's development. Effect of these parameters along with age and pre-storage time on hatching failure leads to embryonic mortality which have been discussed in this study.

Increasing the number of storage days increases the proportion of embryonic mortality during storage and incubation and thereby increased the probability of failure to hatch (Whitehead et al., 1985; Yoo and Wientijes, 1991; Scott and Mackenzie, 1993). Influence of the number of storage days before incubation on proportion of embryo died up to $7^{\text {th }}$ day of incubation, i.e. early embryonic mortality and on the proportion of embryos that died from day 8 to day 21 of incubation, i.e. late embryonic mortality, have been assessed among fertile eggs (Yoo and Wientijes, 1991; Scott and Mackenzie, 1993). There are two phases of increased embryonic mortality during incubation: the first phase occurs during the first week of incubation and the second phase during the last week (Payne, 1919; Byerly, 1930).

Egg shape depends on the anatomical structure of hen, particularly of the oviduct, internal organ distribution and shape of pelvic bones (King'ori, 2011). The egg shape index is the ratio between maximum egg width with maximum egg length (Narushin and Romanov, 2002) and represents a numeric value of egg shape. Many researchers (Narushin and Romanov, 2002; King'ori, 2011) have suggested that the hatching performance achieved with normal shaped eggs are greater than that achieved with abnormal shaped eggs.

Therefore, the aim of our study was to determine the effect of flock age and egg weight, pre-incubation storage period, egg shape index and egg shell thickness on embryonic mortality of Vanaraja Chicken reared under deep litter system of rearing.

\section{Materials and Methods}

The present study was conducted at Hatchery Unit, WBUAFS, Mohanpur campus (Nadia District) under Poultry Seed Project, 2009 on fertile eggs Vanaraja chicken reared under deep litter system for a period from December, 2015 to May, 2016.

\section{Flock information}

Vanaraja chicken were reared in deep litter system with well ventilated and lighted houses. Litter was in good condition i.e. dry, without dust, crust and moulds. There were sufficient feeder (pellet form feed) and automatic drinking (ad libitum) system. Deworming was done monthly. Vaccination was done according to the schedule. Five batches of flock were considered for the study and they were divided into three age groups as 27 to 40,41 to 72 and 73 to 92 weeks.

\section{Egg collection and cleaning}

Total 18 numbers of hatching and 886 numbers of unhatched eggs were observed. Fertile eggs were collected after 2 weeks of first laying at 27 to 40 weeks of age. Eggs 
were collected three times daily, one time in the morning and two times in the afternoon. Eggs were uniform in shape, colour with good sound shell quality were selected for hatching.

\section{Determination of egg weight}

All eggs were weighed individually and recorded daily to the nearest gram and averaged for each replicate by means of electronic digital weighing balance during the whole study and grouped into three category; category $1-38$ to $41.3 \mathrm{~g}$, category $2-41.6$ to $54.8 \mathrm{~g}$, category 3 - more than $55 \mathrm{~g}$.

\section{Storing of fertile eggs}

The eggs were kept in cold storage at $17^{\circ} \mathrm{C}$ and $75 \%$ relative humidity. Eggs were stored with small end pointed downward for 1, 2, 3, 4, 5, 6 days with86, 144, 140, 156, 155, 148 numbers of eggs, respectively, introduced to the setter.

\section{Determination of egg shape index}

Maximum breadth and maximum length was recorded in micrometer to determine the egg shape index of all unhatched eggs. The length and width of the eggs at the broadest points were measured with the help of an electronic ABSOLUTE DIGIMATIC CALIPER (Mututuyo, Japan) sensitive to $0.00 \mathrm{~mm}$.

Shape index was estimated using Shultz (1953) formula:

S.I. (\%): (Egg width/Egg length $) \times 100$

\section{Determination of egg shell thickness}

After exposing the embryo, the shell membrane was separated from shell and its thickness measured. Thickness of broad end, small end and middle of shell was taken and average determined as egg shell thickness and could be considered as a valid measurement of eggshell thickness (mm). The shell thickness of the egg was measured using an electronic ABSOLUTE DIGIMATIC CALIPER (Mututuyo, Japan).

Egg shell thickness $=$ (pointed end + equator + blunt end) $/ 3$

\section{Determination of embryonic mortality}

Early death: Dead in shell within the day 7 of incubation grouped under early death. There was appearance of vascularisation, start of organogenesis, head and trunk was visible, embryo having $\mathrm{C}$ shape with limbs and beak development. Early death (\%) was calculated as number of embryos dying in early phase/number of unhatched eggs x 100 .

Mid death: Dead in shell onward $8^{\text {th }}$ day of incubation till $15^{\text {th }}$ day, categorised under mid death. Feather development starts, limb and eyelid developed, viteline membrane surrounds the yolk sac completely and head turns towards broad end (aircell). Mid death (\%) was calculated as number of embryos dying in mid phase/number of unhatched eggs $\mathrm{x} 100$.

Late death: Dead in shell onwards $16^{\text {th }}$ day of incubation categorised under late death. They were as follows:

$>\quad$ Unabsorbed yolk sac, covered by amnion, unhealed naval or sometimes bloody naval of the embryo was also present.

$>\quad$ Embryo was in pipping position i.e. head was under right wing, full term development dead in shell. An embryo that's full-term and not pipped, with a yolk sac that's large, possibly with residual albumen or not enclosed by the abdominal wall.

$>\quad$ Pierce the inner membrane of shell but dead in shell.

$>\quad$ Pipped or cracked the shell but unable to hatch out. 
Live embryo within the shell but dead after taken out the shell with severe bleeding.

$>\quad$ Anomalies like: crossed beak, missing beak, missing eye, double pair of legs, exposed brain were observed.

Late death $(\%)$ was calculated as number of embryos dying in late phase/number of unhatched eggs x 100.

\section{Statistical analysis}

The replicate pens were the experimental units and all data obtained were pooled replicate wise. The results were expressed as mean, standard error of mean and mean percentage. The data were subjected statistical analysis (Snedecor and Cochran.1994) in the Statistical Package for Social Sciences (SPSS 21.0, Chicago, IL, USA).

\section{Results and Discussion}

\section{Effect of flock age on embryonic mortality}

The effects of flock age on embryonic mortality i. e. early, mid and late death (\%) are tabulated in the table 1 .

The findings demonstrated that there is no significant effect of flock age $(\mathrm{p}>0.05)$ on embryonic mortality. Late death \% (death occurred in last stage of incubation) is occurred maximum insignificantly with a mean percentage of $53.85,53.61$ and 48.93 in 73-92 weeks, 27-40 weeks and 41-72 weeks of flock age respectively than early death (\%) and mid death (\%).

The results of the present study are in tune with the findings of Zakaria et al., (2005), Alsobayel and Albadry (2012), Awad and ElHalim (2014). They also revealed that embryonic mortality was not significantly affected by flock age. However there are some studies which differ from these results viz. Roque and Soares (1994), Lapaoet al., (1999), Almeida et al., (2008), Salahi et al., (2012) found that flock age significantly affected the embryonic mortality in older broiler breeder. In the present study, embryonic mortality irrespective of period of incubation is found to be minimum in 41 to 72 weeks of age of the flock.

\section{Effect of egg weight on embryonic mortality}

The effects of egg weight on embryonic mortality i. e. early, mid and late death (\%) are tabulated in the table 1 .

The observations revealed that there is no significant effect ( $p>0.05)$ of egg weight on embryonic mortality. Early and mid death (\%) were maximum for41.6 to $54.8 \mathrm{~g}$ weighed eggs with a mean percentage of 29.41 and 24.16, whereas late death $(\%)$ occurred mostly when egg weight is more than $55 \mathrm{~g}$ with a mean percentage of 55.08. Lower early, mid and late death (\%) differed in significantly for38-41.3g, >55 $\mathrm{g}$ and 41.6$54.8 \mathrm{~g}$ weighed eggs respectively.

The observations of the present study are consistent with the findings of Fesenko et al., (1992a/b?), Elamin et al., (2015) who concluded that egg weight had no significant effect on embryonic mortality in broiler breeder flocks.

However there are some observations which disagree with these findings; Alabi et al., (2012), Ng'ambiet al., (2013), Rashid et al., (2013), Iqbal et al., (2016) revealed that egg weight significantly affected large sized eggs are associated with higher mortality.

In the present study, embryonic mortality irrespective of period of incubation is found to be minimum in 41.6 to $54.8 \mathrm{~g}$ weighed eggs. 
Effect of pre-incubation storage period on embryonic mortality

The effects of pre-incubation storage period on embryonic mortality i. e. early, mid and late death $(\%)$ are tabulated in the table 1.

The study showed that there is no significant effect $(p>0.05)$ of pre-incubation storage period on embryonic mortality. Early death (\%) is insignificantly highest at $1^{\text {st }}$ day of storage and lowest at $2^{\text {nd }}$ day of storage with a mean percentage of 31.75 and 24.8 respectively. Mid death (\%) is insignificantly highest at 0 day of storage and lowest at $1^{\text {st }}$ day of storage with a mean percentage of 27.85 and 18.25 respectively. Late death (\%) is insignificantly highest at $4^{\text {th }}$ day of storage and lowest at 0 day of storage with a mean percentage of 55.97 and 43.04 respectively.

The findings of the present study are similar with the results of Fasenko et al., (1992a/b?) who observed storage did not affect the embryonic mortality. El-Sagheer (2012) also found that storage of 0 to 5 days had no significant effect on embryonic mortality. However there are some observations which are dissimilar to these findings. Scoot and Mackenzie (1993), Lapaoet al., (1999), Elibolet al., (2002) concluded in their studies the storage had a significant effect on embryonic mortality.

\section{Effect of egg shape index (ESI) on embryonic mortality}

The effects of egg shape index on embryonic mortality i. e. early, mid and late death (\%) are tabulated in the table 2 .

The observations revealed that significant effect $(p<0.05)$ of ESI on embryonic mortality. There is significant difference in embryonic mortality when shape index is $>75 \%$ with both ESI range i.e. 64 to $71.96 \%$ and 72 to $74.97 \%$, but no significant difference existed among $64-71.96 \%$ and $72-$ $74.97 \%$. Highest early and mid death (\%) were found when ESI is more than $75 \%$ with mean percentage of 32.84, 33.87 and highest late death $(\%)$ at 64 to $71.96 \%$ of ESI with mean percentage of 57.33. Lowest early, mid and late death $(\%)$ were observed in 72$74.97 \%, 64-71.96 \%$ and $>75 \%$ of ESI respectively with a mean percentage of 22.15 , 13.33 and 33.58 respectively.

The findings of the present study are in tune with the findings of Asci and Durmus (2015) who observed a significant effect on ESI. However Jull and Haynes (1925) and Brar et al., (2006) revealed that there was no significant contribution of egg shape index in embryonic mortality.

\section{Effect of egg shell thickness on embryonic mortality}

The effects of egg shell thickness on embryonic mortality i. e. early, mid and late death (\%) are tabulated in the table 2.

The findings demonstrated a significant effect $(p<0.05)$ of shell thickness on embryonic mortality. There is significant difference in embryonic mortality when shell thickness is $0.22 \mathrm{~mm}$ to $0.31 \mathrm{~mm}$ with both shell thickness groups i. e. $0.15-0.21 \mathrm{~mm}$ and $>0.32 \mathrm{~mm}$, but no significant differences were found in between $0.15-0.21 \mathrm{~mm}$ and $>0.32 \mathrm{~mm}$ shell thickness groups. At $0.22 \mathrm{~mm}$ to $0.31 \mathrm{~mm}$ highest early death $(\%)$ occurred with a mean percentage of 33.33, highest mid death (\%) occurred at $0.15 \mathrm{~mm}$ to $0.21 \mathrm{~mm}$ shell thickness with a mean percentage of 25.77 and highest late death (\%) occurred when shell thickness is more than $0.32 \mathrm{~mm}$ with a mean percentage of 73.91 .

The observations of the present study are in consonance with the results of Farooq et al., (2001) and Murad et al., (2001) who also found significant influences of egg shell 
thickness on embryonic mortality. However there are some observations on contrary of these findings, Elamin et al., (2015), Malik et al., (2015) revealed that egg shell thickness showed no significant effect on embryonic mortality. The effect of egg shell thickness on embryonic mortality at different stages of incubation may be due to inadequate nutrition of the parent stock.

Table.1 Effect of flock age, egg weight and pre-incubation storage on embryonic mortality of Vanaraja Chicken eggs

\begin{tabular}{|c|c|c|c|c|c|c|c|c|c|c|c|c|c|}
\hline \multirow{2}{*}{$\begin{array}{l}\text { Embryonic } \\
\text { mortality (\%) }\end{array}$} & \multicolumn{3}{|c|}{ Flock age (weeks) } & \multicolumn{3}{|c|}{ Egg weight (g) } & \multicolumn{7}{|c|}{ Pre-incubation storage (days) } \\
\hline & $27-40$ & $41-72$ & $73-92$ & $38-41.3$ & $41.6-54.8$ & $>55$ & 0 & 1 & 2 & 3 & 4 & 5 & 6 \\
\hline Early death \% & 22.89 & 28. & 27.69 & 23.18 & 29.41 & 26 & 9.11 & 31.75 & 24.8 & 24.11 & 25.3 & 30.71 & 27.81 \\
\hline Mid d & 23.49 & 22.39 & 18.46 & 23.18 & 6 & 18.36 & 27.85 & 18.25 & 20.80 & 24.82 & 18.66 & 23.62 & 23.84 \\
\hline Late death \% & 53.61 & 48.93 & 53.85 & 53.64 & 46.43 & 55.08 & 43.04 & 50 & 54.40 & 51.06 & 55.97 & 45.67 & 48.34 \\
\hline
\end{tabular}

Table.2 Effect of egg shape index and egg shell thickness on embryonic mortality of Vanaraja Chicken eggs

\begin{tabular}{|c|c|c|c|c|c|c|}
\hline Embryonic mortality (\%) & \multicolumn{3}{|c|}{ Egg shape index (\%) } & \multicolumn{3}{c|}{ Egg shell thickness(mm) } \\
\hline & $64-71.96$ & $72-74.97$ & $>75$ & $0-0.21$ & $0.22-0.31$ & $>0.32$ \\
\hline Early death \% & $29.33^{\mathrm{a}}$ & $22.15^{\mathrm{a}}$ & $32.84^{\mathrm{b}}$ & $14.43^{\mathrm{a}}$ & $33.33^{\mathrm{b}}$ & $14.49^{\mathrm{a}}$ \\
\hline Mid death \% & $13.33^{\mathrm{a}}$ & $26.35^{\mathrm{a}}$ & $33.87^{\mathrm{b}}$ & $25.77^{\mathrm{a}}$ & $19.37^{\mathrm{b}}$ & $11.59^{\mathrm{a}}$ \\
\hline Late death \% & $57.33^{\mathrm{a}}$ & $51.49^{\mathrm{a}}$ & $33.58^{\mathrm{b}}$ & $59.79^{\mathrm{a}}$ & $47.29^{\mathrm{b}}$ & $73.91^{\mathrm{a}}$ \\
\hline Significant & \multicolumn{3}{|c|}{$\begin{array}{c}\text { Values bearing different } \\
\text { superscripts (a, b) within the row } \\
\text { differ significantly(p<0.05) }\end{array}$} & $\begin{array}{c}\text { Vapering different } \\
\text { sulfipts (a, b) within the row } \\
\text { differ significantly(p<0.05) }\end{array}$ \\
\hline
\end{tabular}

Based on the result of this study it can be concluded that embryonic mortality was not affected by egg weight, flock age and preincubation storage period. Whereas egg shell thickness and egg shape index affect the embryonic mortality. It was seen that at later stage of embryonic development the maximum mortality occurred, at $64-71.96 \%$ egg shape index and an increase shell thickness also cause a higher embryonic mortality. So as far as embryonic mortality is concerned, egg shape index and egg shell thickness impart directly to the economic contribution of Vanaraja chicken.

\section{Acknowledgement}

The authors would like to thank all the staffs of Dept, of Livestock Production Management, WBUAFS, Kolkata.

\section{References}

Alabi, O. J., Ng`ambi, J. W. and Norris, D. 2012. Effect of egg weight on physical egg parameters and hatchability of indigenous Venda chickens. Asian Journal of Animal and Veterinary Advances, 7(2):166-172.

Alexis and Romanoff, L. (1949). Critical periods and causes of death in avian embryonic development. Auk. 66: 264270.

Almeida, J. G., Vieira, S. L., Reis, R. N., Berres, J., Barros, R., Ferreira, A. K. and Furtado, F. V. F. 2008. Hatching distribution and embryo mortality of eggs laid by broiler breeders of different ages. Brazilian Journal of Poultry Science, 10(2): 89-96.

Alsobayel, A.A. and Albadry, M.A. 2012. 
Effect of age and sex ratio on fertility and hatchability of baladi and leghorn laying hens. Journal of Animal and Plant Science, 22: 15-19.

Aşc1, E. and Durmuş, İ. (2015). Effect of egg shape index on hatching characteristics in hens. Turkish Journal of Agriculture. 3(7): 583-587.

Awad, A. L. and Abd El-Halim, H. A. H. (2014).Some hatching traits in sinai chicken eggs as affected by flock age, dietary ascorbic acid supplementation and egg storage period under Egyptian conditions. Egyptian Poultry Science Journal. 34(IV): 959-978.

Birkhead, T. R., Hall, J., Schut, E. and Hemmings, N. (2008). Unhatched eggs: methods for discriminating between infertility and early embryo mortality. Ibis. 105:1-10.

Brar, A. K., Brah, G. S. and Chaudhary, M. L. (2006). Analysis of relationship of egg weight and specific gravity with incubation mortality in chickens. Indian Journalof Poultry Science. 41(2): 122 128.

Byerly, T. C. (1930). Time of occurrence and probable causes of mortality in chick embryos. Proceedings of World's Poultry Congress. 4: 178-186.

Elamin, M. K., Malik, H. E. E., Sakin, A. I. Y., Elagib, H. A. A. and Dousa, B. M. (2015). Effect of egg weight and egg shell thickness on hatchability and embryonic mortality of cobb broiler breeder eggs. Global journal of animal scientific research. 3(1): 186-190.

Elibol, O., Peak, S. D., and Brake, J. (2002) Effect of flock age, length of egg storage, and frequency of turning during storage on hatchability of broiler hatching eggs. Poultry Science. 81(7) :945-50.

El-sagheer, M. (2012). Influence of preincubation storage duration on egg quality, hatchability, embryonic mortality and viability of Dandarawi chicks. Egyptian Journal of Animal Production. 49(2): 173-180

Farooq, M., Mian, M. A., Murad, A., Durrani, F. R., Asghar, A. and Muqarrab, A. K. (2001). Egg traits of Fayumi birds under subtropical conditions. Sarhad Journal of Agriculture. 17(2): 141-145.

Fasenko, G. M., Hardin, R. T., Robinson, F. E. and Wilson, J. L. (1992a). Relationship of hen age and egg sequence position with fertility, hatchability, viability, and preincubation embryonic development in broiler breeders. Poultry Science. 71(8): 1374-83

Fasenko, G. M., Robinson, F. E., Hardin, R. T., and Wilson, J. L. (1992b). Variability in pre-incubation embryonic development in domestic fowl and effects of duration of egg storage period. Poultry Science.71(12):2129-32.

Iqbal, J., Khanb, S. H., Mukhtara, N., Ahmed, T. and Pashad, R. A. (2016). Effects of egg size (weight) and age on hatching performance and chick quality of broiler breeder. Journal of Applied Animal Research. 44(1): 54-64.

Jull, M. A. and Haynes, S. (1925). Shape And weight of eggs in relation to their hatching quality. Journal of Agricultural Research. 31(7): 685-694.

King'ori, A. M. (2011). Review of the factors that influence egg fertility and hatchability in poultry. International Journal of Poultry Science. 10(6): 483492.

Lapao, C., Gama, L. T. and Soares, M. C. (1999). Effects of broiler breeder age and length of egg storage on albumen characteristics and hatchability. Poultry Science.78: 640-645.

Lyons, J. J. (2003). Small flock series: incubation of poultry. An Agricultural Publication. G8353.

Malik, H. E. E., Sakin, A. I. Y., Elagib, H. A. 
A., Dousa, B. M. and Elamin, K. M. (2015). Effect of egg weight and egg shell thickness on hatchability and embryonic mortality of Cobb broiler breeder eggs. Global Journal of Animal Scientific Research. 3(1): 186-190.

Murad, A., Farooq, M., Mian, M. A., Muqarrab, A. K. (2001). Hatching performance of Fayumi eggs. Sarhad Journal of Agriculture. 17(1): 1-6.

Narushin's, V. G. and Romanov, M. N. (2002). Egg physical characteristics and hatchability. World's Poultry Science Journal.58: 297-303.

Ng'ambi, J. W., Thamaga, M. W., Norris, D., Mabelebele, M. and Alabi, O. J. (2013). Effects of egg weight on hatchability, chick hatch-weight and subsequent productivity of indigenous Venda chickens in Polokwane. South African Journal of Animal Science. 43(5): 6974.

Payne, L. F. (1919). Distribution of mortality during the period of incubation. J. Am. Assoc. Instr. Invest. Poultry Husb.6: 912.

Rashid, A., Khan, S. H., Abbas, G., Amer, M. Y., Khan, M. J. and Iftikhar, N. (2013). Effect of egg weight on hatchability and hatchling weight in Fayoumi, Desi and crossbred (Rhode Island Red X Fayoumi) chickens. Vetworld. 6(9): 592-595.

Roque, L. and Soares, M. C. (1994). Effects of Eggshell Quality and Broiler Breeder Age on Hatchability. Poultry Science
Association. 73(12):1838-1845.

Salahi, A., Khabisi, M. M. and Esmailizadeh, A. K. (2012). Effects of pre-incubation upside-down positioning of eggs from breeder flocks with different ages on hatchability and chick quality. Animal Production Science. 52: 269-275.

Scott, T. A. and Mackenzie. C. J. (1993). Incidence and classification of early embryonic mortality in broiler breeder chickens. British Poultry Science. 34: 459-470.

Shultz, F.T. (1953). Analysis of egg shape of chicken. Biometrics. 9: 336-353.

Snedecor, G. W. And Cochran, W. G. (1994). Statistical methods. $8^{\text {th }}$ ed.Iowa State University Press, Ames, Iowa.

Whitehead, C. C., Maxwell, M. H., Pearson, R. A., and Herron, K. M. (1985). Influence of egg storage on hatchability, embryonic development and vitamin status in hatching broiler chicks. British Poultry Science. 26(2):221-8.

Yoo, B. H., and Wientjes, E. (1991). Rate of decline in hatchability with preincubation storage of chicken eggs depends on genetic strain. British Poultry Science. 32: 733-740.

Zakaria, A. H., Plumstead, P.W., RomeroSanchez, H., Leksrisompong, N., Osborne, J. and Brake, J. (2005). Oviposition pattern, egg weight, fertility, and hatchability of young and old broiler breeders. Poultry Science. 84(9):1505-9.

\section{How to cite this article:}

Sujata Dey, Rajarshi Samanta, Subhransu Pan, Bikas Debnath and Asish Debbarma. 2019. Factors Associated with Embryonic Mortality of Eggs of Vanaraja Breeder Chicken Reared on Deep Litter System. Int.J.Curr.Microbiol.App.Sci. 8(04): 525-532. doi: https://doi.org/10.20546/ijcmas.2019.804.057 